\title{
COST EVALUATION OF STROKE THERAPY COMPARED TO INA- CBGs ON INPATIENTS AT ANUTAPURA HOSPITAL
}

\author{
Muhamad Rinaldhi Tandah ${ }^{1}$, Alwiyah Mukaddas ${ }^{1}$, Dewi Angriani ${ }^{1}$, Gaby Nathania \\ Angela Mangoting ${ }^{1}$ \\ ${ }^{1}$ Department of Pharmacy, Tadulako University, Palu, Sulawesi Tengah, Indonesia \\ Corresponding address: Muhamad Rinaldhi Tandah \\ Email: prof.aldhi@gmail.com
}

\begin{abstract}
Stroke is the third cause of death in the world after heart disease, cancer, and disability including disability categorized based on its severity: mild (I), moderate (II), and severe (III) severity. This study aims to determine the difference total cost of ischemic and hemorrhagic stroke therapy, each, with INA-CBGs rates. The method of data collection was conducted retrospectively taken from medical record data, and on patient medical expenses. The subject were ischemic and hemorrhagic stroke patients hospitalized from 2016-2017 at Anutapura Hospital who met the inclusion and exclusion criteria. There were 134 patients who met the inclusion criteria, $68 \%$ were ischemic stroke patients and $32 \%$ were hemorrhagic stroke patients. The result of research showed that there were significant differences in costs $(p<0.05)$ between hospital real costs and INA-CBGs rates. The average total real cost of treatment for ischemic stroke therapy was IDR 7,360,196.70 and the cost of the INA-CBGs was IDR 7,427,251.65 for 91 inpatients; and the average total cost of patients with hemorrhagic stroke therapy took IDR $10,606,834.34$ with average of INA CBG's rate at IDR 4,399,393.02 for 43 inpatients. The conclusion is both of stroke therapy proved significant difference compared to BPJS claimed amount of money.
\end{abstract}

Keywords: pharmacoeconomic, cost analysis, ischemic stroke, haemorrhage stroke, INACBG's rate.

\section{INTRODUCTION}

Stroke is a term used to define neurological changes caused by the interruption of blood flow to the brain. Stroke is classified into two categories, namely ischemic and haemorrhagic. Ischemic stroke occurs due to a blockage of blood flow; the blood flow to the brain is suddenly blocked caused by atherosclerosis (Powers et al., 2015). Haemorrhagic stroke rarely happens, it may cause severe consequences and high mortality rates. Typical clinical symptoms of haemorrhagic stroke include headache, vomiting, consciousness disturbance, and mental disorders. Most bleeding sites are located in cerebellar hemisphere and temporal lobe. A cerebrospinal fluid (CSF) leakage caused by surgeries may be the key to intracranial haemorrhages happening. Early diagnosis and treatments are very important for patients to prevent the further progression of intracranial 
haemorrhages. Several patients need a hematoma evacuation and their prognosis is not optimistic (Yang et al., 2017).

Nationally, the prevalence of stroke in Indonesia in 2018 based on a doctor's diagnosis in the population aged $\geq 15$ years old is $10.9 \%$, or an estimated $2,120,362$ people. The provinces of East Kalimantan (14.7\%) and Special Region of Yogyakarta (14.6\%) are provinces with the highest prevalence of stroke in Indonesia. Meanwhile, Papua and North Maluku have the lowest stroke prevalence compared to other provinces, respectively $4.1 \%$ and 4.6\% (Budijanto et al., 2019).

The older an individual get, the more cardiovascular problems they experienced. In a limited study in an urban community clinic, $72 \%$ of elderly people with hypertension were found to be higher than prevalence of the national report which is. $25 \%$. Amount of respondent as much as $38 \%$ gave abnormal ECG images, which are $5 \%$ of those had myocardial infarction and 3\% had inferior ischemic (Armalina et al., 2020). A research at Panembahan Senopati Hospital (Bantul) obtained a relationship between hypertension $(\mathrm{RP}=9,000 ; \mathrm{CI}=4,866-16,645 ; \mathrm{p}$ value $=0,000)$ and diabetes mellitus $(\mathrm{RP}=4,226 ; \mathrm{CI}=3.089-5,780 ; \mathrm{p}$ value $=0.000)$ due to stroke occurrence (Sofiana \& Rahmawati, 2019). The funding of the treatment of stroke which has been regulated based on the rates of INA-CBGs requires the hospital to carry out quality control and maintenance costs as efficient as possible. Thus, this study aims to determine difference between cost of treatment (both type of stroke) with the amount of money that can be claimed by the hospital, and also count with t-test to confirm it statistically.

\section{METHOD}

This study was a pharmacoeconomic study using a descriptive research design with retrospective data collection. Data were collected taken from the medical record room and the financial department of Anutapura Hospital within year of 2016 and 2017. This study was conducted using CA (Cost Analysis). The population were the inpatients of stroke which were BPJS recipients. The inclusion criteria were patients with the main diagnosis of ischemic stroke or haemorrhagic stroke, which got treatment in room class I, II, and III, have completed proof of payment, and severity levels I, II, and III. There were 483 stroke patients who were hospitalized from 2016-2017, which were 91 ischemic patients and 43 haemorrhagic patients who met the criteria. This research has been given permitted by the ethics committee of Faculty of Medicine, University of Tadulako No. $8718 / \mathrm{UN} 28.1 .30 / \mathrm{KL} / 2020 \quad$ at December 112020.

Data analysis was
performed descriptively to
determine patient characteristics,


treatment features, and cost during

treatment.

\section{RESULTS}

Table 1. Demographic Characteristics

\begin{tabular}{lcccc}
\hline \multirow{2}{*}{ Characteristics } & \multicolumn{2}{c}{ Ischemic (n=91) } & \multicolumn{2}{c}{ Haemorrhagic (n=43) } \\
\cline { 2 - 5 } Amount & Percentage & Amount & Percentage \\
\hline Male & 47 & $51,65 \%$ & 19 & $44,19 \%$ \\
Female & 44 & $48,35 \%$ & 24 & $55,81 \%$ \\
\hline Age & 3 & & & \\
$22-30$ & 4 & $3,30 \%$ & 3 & $6,98 \%$ \\
$31-39$ & $4,40 \%$ & 7 & $16,28 \%$ \\
$40-48$ & 34 & $15,38 \%$ & 16 & $37,21 \%$ \\
$49-57$ & $37,36 \%$ & 7 & $16,28 \%$ \\
$58-66$ & 27 & $29,67 \%$ & 5 & $11,63 \%$ \\
$67-75$ & 9 & $9,89 \%$ & 5 & $11,63 \%$ \\
\hline Educational Background & & & & \\
Not educated & 2 & $2,20 \%$ & 0 & $0,00 \%$ \\
Elementary school & 5 & $5,49 \%$ & 0 & $0,00 \%$ \\
Middle school & 18 & $19,78 \%$ & 7 & $16,28 \%$ \\
High school & 41 & $45,05 \%$ & 25 & $58,14 \%$ \\
Higher Education & 25 & $27,47 \%$ & 11 & $25,58 \%$ \\
\hline Occupation & & & & \\
Civil servants & 21 & $23,08 \%$ & 8 & $18,60 \%$ \\
Retirement & 4 & $4,40 \%$ & 4 & $9,30 \%$ \\
Private employee & 15 & $16,48 \%$ & 10 & $23,26 \%$ \\
Housewife & 21 & $23,08 \%$ & 15 & $34,88 \%$ \\
Entrepreneur & 30 & $32,97 \%$ & 6 & $13,95 \%$ \\
\hline
\end{tabular}

The description of the research subjects in table 1 showed that 118 patients who met the inclusion criteria. Patients with a primary diagnosis of ischemic stroke were 91 patients $(68 \%)$ and haemorrhagic strokes were 43 patients $(32 \%)$.

Ischemic stroke can occur at any age. The result indicates that age increases the risk of stroke.
Stroke did not only occur in elderly people, but also occurs at productive age under 54 years; there are even stroke patients under the age of 30 years old.

Duration of patients been taking care by the hospital play a significant role which charge as long as they have been treated, since it was calculated per day of hospitalization (as seen in table 2).

Table 2. Length of Stay 


\begin{tabular}{lcc}
\hline \multicolumn{1}{c}{ Length of Stay } & Ischemic patient $(\mathbf{n = 9 1})$ & Hemorrhagic patient $(\mathbf{n}=\mathbf{4 3})$ \\
\hline$<5$ days & 15 & 4 \\
$5-10$ days & 66 & 14 \\
$>$ 10 days & 10 & 25 \\
\hline
\end{tabular}

To conduct cost analysis radiology, medicine, medical comprehensively, this research devices, medical treatment, doctor needed to choose its point of view. visit, physiotherapy, and treatment The study used hospital perspective, room. Specifically, it can be seen in parts of cost that collected were the the table below. expense of laboratory, consultation,

Table 3. Cost components by each type of stroke patient

\begin{tabular}{lrrrr}
\hline \multirow{2}{*}{ Cost Components } & \multicolumn{2}{c}{ Ischemic stroke } & \multicolumn{2}{c}{ Hemorrhagic stroke } \\
\cline { 2 - 5 } & Cost (IDR) & \% & \multicolumn{1}{c}{ Cost (IDR) } & \multicolumn{1}{c}{$\%$} \\
\hline Laboratory & $33,248,000$ & 8.55 & $21,371,378$ & 4.54 \\
Consultation & $1,210,000$ & 0.31 & 990,000 & 0.21 \\
Radiology & $33,380,000$ & 8.59 & $31,550,000$ & 6.70 \\
Medicine & $87,019,468$ & 22.38 & $146,115,094$ & 31.01 \\
Medical devices & $19,114,749$ & 4.92 & $20,043,971$ & 4.25 \\
Medical treatment & $48,791,800$ & 12.55 & $75,796,002$ & 16.09 \\
Doctor visit & $5,005,200$ & 1.29 & $19,412,800$ & 4.12 \\
Physiotherapy & $10,919,000$ & 2.81 & $4,725,000$ & 1.00 \\
Room & $150,090,000$ & 38.61 & $151,120,000$ & 32.08 \\
\hline
\end{tabular}

The cost of haematological examinations issued by each patient varies depending on the type of examination and the frequency of examination. And as for the types of haematological examinations carried out, namely examination of total glucose, intermittent glucose, fasting glucose, total cholesterol, creatinine, $\mathrm{Na}, \mathrm{K}, \mathrm{Cl}$, uric acid High Density Lipoprotein (HDL), Low Density Lipoprotein (LDL), Serum Glutamic

Oxaloacetik Transaminase (SGOT), Serum Glutamic Pyruvate Transaminase (SGPT), triglycerides, urea $\mathrm{N}$, Hepatitis B Surface Antigen (HBsAG), blood type, clotting time, bleeding time, anti HCV, Red Blood
Cell (RBC), haemoglobin, haematocrit, Mean Corpuscular Haemoglobin (MCH), Mean Corpuscular Volume (MCV), Mean Corpuscular Haemoglobin Concentration (MCHC), Red blood cell Distribution Width Coefficient Of Variation (RDWcv), Red blood cell Distribution Width Standard Deviation (RDWsd), platelets, Mean Platelet Volume (MPV), Procalcitonin (PCT), Platelet Distribution Width (PDW), and White Blood Cell (WBC).

To be compared properly, all of those fees in table 4 grouped into the room where the patient healed. Preference room of treatment of each patient were 
depending on which grade of BPJS had been paid. Otherwise, Anutapura Hospital located on capital city of Central Sulawesi and has become referral hospital for years, which is being one of preferable health care in the city.

Table 4. Class of Treatment

\begin{tabular}{|c|c|c|c|c|c|c|}
\hline \multirow[b]{2}{*}{ Characteristics } & \multicolumn{3}{|c|}{ Ischemic $(\mathrm{n}=91)$} & \multicolumn{2}{|c|}{ Hemorrhagic $(n=43)$} & \multirow[b]{2}{*}{ Average } \\
\hline & $\underset{t}{\operatorname{Amoun}}$ & $\begin{array}{l}\text { Total } \\
\text { cost }\end{array}$ & Average & Amount & Total cost & \\
\hline \multicolumn{7}{|l|}{ Treatment } \\
\hline Class I & 41 & $\begin{array}{c}71.000 \\
.000\end{array}$ & 1.731 .707 & 8 & 24.000 .000 & 3.000 .000 \\
\hline Class II & 15 & $\begin{array}{c}18.000 \\
.000\end{array}$ & 1.200 .000 & 1 & 1.950 .000 & 1.950 .000 \\
\hline Class III & 35 & $\begin{array}{c}34.800 \\
.000\end{array}$ & 994.286 & 21 & 24.120 .000 & 1.148 .571 \\
\hline ICU & - & - & - & 13 & 57.600 .000 & 3.840 .000 \\
\hline
\end{tabular}

To explore the impact of cost by both type of stroke, it can be seen in table 5 below. Even though ischemic stroke gave added value to the hospital, the loss generated by haemorrhagic stroke treatment cannot be ignored.

Table 5. Comparison between Real Cost and INA-CBGs in Stroke Patients

\begin{tabular}{ccc}
\hline \multirow{2}{*}{ Rate } & \multicolumn{2}{c}{ Total cost (IDR) } \\
\cline { 2 - 3 } & Ischemic stroke & Hemorrhagic stroke \\
\hline INA-CBGs & $675,879,900.00$ & $189,173,900.00$ \\
Real cost & $669,777,900.00$ & $456,093,877.00$ \\
Difference & $-6,102,000.00$ & $266,919,977.00$ \\
\hline
\end{tabular}

Using Microsoft Excel to see the difference statistically, it has $t_{\text {count }}$ 3.99 and $\mathrm{t}_{\text {table }} 1.98$ which mean there was significant difference between stroke therapy which paid by the hospital and the insurance.

\section{DISCUSSION}

Incident of stroke did not tend to any gender. Group of ischemic stroke dominated by men, but hemorrhagic stroke cases showed either way. Probable reason of men underlined in ischemic stroke is might caused by several risk factors in daily lifestyle such as smoking, hypertension, diabetes mellitus, dyslipidemia, and other diseases. Strokes tend to occur to men due to smoking habits. Estrogen in women plays as a protector in preventing the process of atherosclerosis. The reason women were more susceptible to stroke was related to contraception, obesity, pregnancy, and menopause.

The age correlated with stroke due to the unhealthy lifestyle such as smoking, unhealthy food, 
and lack of physical activities. This result is supported by Suiraoka (2012) stated that strokes can be experienced by various age groups. Stroke at productive age often occurs due to busy work that causes a person to insufficient time to rest, irregular eating patterns, lack of exercise, excessive working hours, severe stress, and consumption of fast food (Dourman, 2013). Age is a risk factor for stroke, the higher the age, the risk for stroke also increases. Stroke can affect all age groups, especially the largest cases occur in elderly patients, which is related to the process of degeneration (aging) that occurs naturally, where at certain age all organs of the body experience a decline in function.

This can also be seen from the average value which shows that there was significant difference between each group. Of the total hospital costs per patient, it is showed that age affect the cost of stroke therapy. Only the average cost for each age group is different. This result is supported by Baroroh \& Fauzi (2017) which shows no significant difference in the total cost of each patient in the age group.

Hematological examination was carried out on the first day the patient was admitted to the hospital, the aim was to find out any abnormalities that occurred in the patient. However, in patients with a history of certain diseases, hematological examinations were carried out more than once to control the patient's condition until it improved. The type of hematological examination above is carried out with the aim of knowing what factors can affect the occurrence of ischemic stroke. For the parameters of recovery of ischemic stroke patients at Anutapura General Hospital, the most important is determined based on the general condition of the patient such as monitoring of neurological development such as failure to have the ability to have neurological functions that should be possessed due to lesions (defects) of the brain that occur in the early period of brain growth and monitoring blood pressure.

was the main supporting
examination to establish the diagnosis in ischemic stroke patients. There are 3 types of radiological examination, namely CT-Scan examination, radio diagnostic, ultrasonography examination. The cost for a onetime CT scan is Rp. 925,000.00 the cost for one time radio diagnostic/simple examination is Rp. 188,000.00 and the fee for a one-time examination is 188,000.00. The purpose of CTScan examination is to distinguish the type of stroke and identify the type of stroke that occurs due to blockage of blood vessels in the brain. Therefore, the costs incurred for this CT-Scan examination are quite expensive compared to radiology/simple examinations and radiological/ultrasonographic examinations.

Medical treatment or rehabilitation was only reserved for 
patients who need to receive medical rehabilitation, of which only 54 patients received with a total cost Rp. 10,919.000.00 and an average of Rp. 202,203.70. Types of medical rehabilitation that patients receive in the form of physiotherapy include exercise therapy, which consists of balance and coordination exercises, and functional exercises. This medical rehabilitation is carried out on patients who need special training to improve nerve (neurological) function in achieving maximum improvement through physical therapy and other techniques. Medical rehabilitation is very important to return patients to be independent, take care of themselves, and do the activities of daily life without being a burden to their families.

The length of stay is based on the patient being registered as an inpatient. The length of treatment is likely to be affected by the presence of other risk factors (comorbid), because other risk factors also need to be treated, besides the stroke. Patient multimorbidity, specifically hypertension, is a strong predictor of longer stay and cost after ICH. The non-linear relationship between cost and time should also be considered when forecasting healthcare spending in these patients (Specogna et al., 2017).

Seeing more detail to the medicine that has been taken, diagram 1 illustrates utilization of the drug based on the indication. The use of peripheral vasodilators and cerebral activators is used as the focus of therapy in ischemic stroke patients. This class of drugs works as an activator of brain function and functions as a dilate of peripheral blood vessels (Junaidi, 2011). Citicolin is useful for treating one of the diseases, namely stroke to reduce the accumulation of fatty acids in the area of nerve damage.

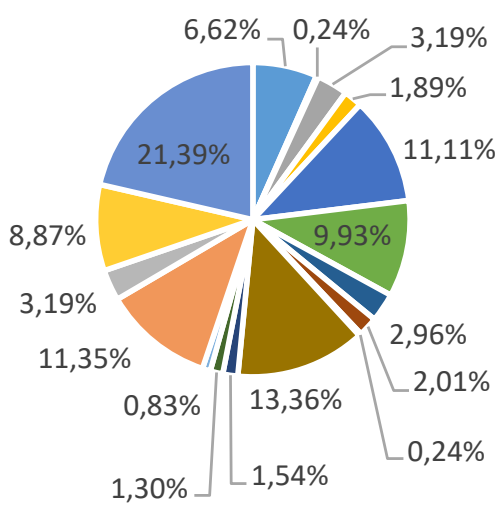

- Analgesic, Antipiretic \& Antiinflamation

- anti asthma

- Antibiotic

- Antidiabetic

- Anticoagulan, Antifibrinolitic

- Antihypertension

- Anticholesterol

- Anticonvulsan

- Antimigrain

- Anti ulcer

- Anti vertigo

- Diuretic

- Laxative

- Nootropik \& Neurotonic

- Water for injection

- Peripheral Vasodilators

- Vitamin, Mineral, \& Electrolite

Diagram 1. Drug utillization

The nootropic and neurotonic drugs are also used as a focus of therapy in ischemic stroke patients, neurotropic drugs are used in cerebral insufficiency, which refers to a decrease in blood supply to the brain such as forgetfulness, lack of concentration, and vertigo. This class of drugs also functions as a brain booster or brain vitamin, in 
this study piracetam became the main choice for ischemic stroke patients at Anutapura Hospital, piracetam can improve motor skills and prevent wider brain damage in patients

In this study, the use of antihypertensive drugs in ischemic stroke patients can improve the patient's functional output when cerebral vasospasm occurs and can inhibit the occurrence of atherosclerosis which is one of the causes of ischemic stroke. The main reason for lowering blood pressure is to prevent bleeding in the brain. The drug amlodipine can work to lower high blood pressure and help prevent stroke.

Mannitol is an osmotic drug with a diuretic class which is used as the main therapy in ischemic stroke to reduce brain and intracranial edema by withdrawing fluid from edematous and nonedematous brain tissue, a diuretic drug that is also used in anutapura hospital, namely furosemide tablets.

Antibiotic therapy is necessary for stroke patients due to infection. In general, patients who are hospitalized with this type of infection occur because of the severity of the underlying neurological disease such as bleeding from a subarachnoid aneurysm or severe trauma due to brain injury, cross contamination, contaminated instruments and needles, and also the environment (Qayyum, 2010). Ceftriaxone is an antibiotic used to treat a variety of bacterial infections.
Analgesic, antipyretic and anti-inflammatory drugs are applied as supportive therapy for ischemic stroke. Moreover, Ketorolac, santagesic, and kamolas as nonsteroidal anti-inflammatory drugs function to treat moderate and severe pain. Paracetamol functioned as analgesic and antipyretic which lower body temperature and prevent fever in ischemic stroke patients. Analsik can also be used for pain relief. It contains two combinations of active substances that reacted on the brain and nerves (central nervous system) to produce a calming effect. Dexamethasone is a class of corticosteroids that prevent and reduce the inflammatory process and reduce histamine release.

Antiulcer is used in ischemic stroke therapy to reduce stomach acid. The drug used is omeprazole, which belongs to the anti ulcerative class. It treats gastric ulcers by reducing gastric acid secretion, while other supporting drugs in ischemic stroke therapy used to control stomach acid are the proton pump group. Inhibitors can be specified into types such as antacids.

In ischemic stroke therapy, the use of tranexamic acid is the main choice as an antifibrinolytic that functions to reduce the risk of rebleeding. The antiplatelet used is clopidogrel. Generally, this class of drugs is used in stroke patients to prevent recurrent strokes and prevent platelet aggregation (Jauch, 2013). 
Anticoagulants, antiplatelets $\&$ Fibnolytics are utilized to repair blood clots in infarcted brain areas. Rinclo contains CPG, which is widely used to prevent atherothrombotic events in ischemic stroke myocardial infarction. Thrombo aspirin functions as a blood-thinning drug that functions to prevent blood clots and reduce the risk of heart attack and ischemic stroke to relieve and treat nausea and gastrointestinal disorders.

Anticholesterol is also a supporting therapy in ischemic stroke patients, where the statin group is used, this group is one of the strong cholesterol-lowering drugs (Low Disity Lipoprotein/LDL) in the blood. Antidiabetic is a stroke support therapy to reduce excessive blood sugar levels. In the case of hemorrhagic stroke, hyperglycemia must be reduced immediately because it can expand the infarct area due to a lack of oxygen forces.

Stolax suppo is a supportive therapy as a laxative to overcome problems in the digestive tract, not only stolax but also other drugs are used to treat the digestive tract in stroke patients, such as dulcolax suppo.

In this study, the use of anticonvulsant drugs in ischemic stroke patients is to restore the stability of nerve cell excitability and overcome seizures. Gabapentin is used to prevent and control seizures in ischemic stroke, while alpentin works by reducing the release of neurotransmitters (signal carriers) that cause seizures.
Impaired fluid and electrolyte balance are serious problems affecting the pathophysiology of ischemia in the brain and often cause brain herniation and death. The use of electrolyte fluids serves to replace fluid loss due to dehydration and hypovolemic shock in stroke patients. The electrolyte fluids used here are Ringer's lactate infusion, INF asering fluid, Nacl fluid, Nacl infusion fluid, futrolite fluid, and M20 infusion. In ischemic stroke therapy, neutropic vitamins such as mecobalamin, neurodex, selesbion, vitamin $\mathrm{B} 1$, vitamin $\mathrm{B} 6$, vitamin $\mathrm{B} 12$, and vitamin $\mathrm{C}$ are involved. To treat hypoglycemia in stroke patients, Martos infusion is given. Other supporting drug, aquadest, is used as a drug solvent.

Presidential Regulation of the Republic of Indonesia No.12 2013 on Health Insurance organized by the Health Social Security Organizing Agency (BPJS Kesehatan) states that per January 1st, 2014 all citizens of Indonesia will receive guarantees in the form of health maintenance and protection in meeting basic health needs. Thus, health facility payment for inpatients is based on Indonesian Case-Based Groups (INA-CBGs). In the INA-CBGs system, the cost component being included in BPJS insurance. Such insurance consists of treatment, stay, medicine, medical devices, and services calculated integrated with the package.

The Regulation of the Minister of Health of the Republic 
of Indonesia No. 522016 has stipulated the standard of health service rates in the implementation of health insurance programs that regulate the rate of INA-CBGs that is the number of claims paid by BPJS Kesehatan to the Advanced Level Health Facilitator Reference for service packages based on diagnosis and procedure. In the main diagnosed group ischemic stroke with the code INA-CBGs, there is G-4-14 for non-specific cerebral blood vessels. In precerebral blockages without infarction and hemorrhagic stroke with the code INA-CBGs, there is G-4-13 for intracranial hemorrhage rather than traumatic. The classification of it is as follows: mild (I), moderate (II), and severe (III). Based on the Regulation of the Minister of Health of the Republic of Indonesia No. 52 2016, the rate of INA-CBGs for ischemic strokes with code G-4-14-I class 3 is IDR $6,146,000$, class 2 is IDR 7,375,700, class 1 is IDR 8,604,400, for G-414-II code class 3 is IDR 7,334,900, class 2 is IDR $8,801,900$, class 1 is IDR 10,268,900, and code G-4-14III class 3 is IDR $10,352,600$, class 2 is IDR $12,423,100$, class 1 is IDR $14,493,600$; and the rate of hemorrhagic stroke with the code of G-4-13-I INA-CBGs in class 3 is IDR $3,658,700$, class 2 is IDR $3,658,500$, class 1 is IDR 4,268,200. The rate of INA-CBGs of G-4-13-II for class 3 is IDR 5,316,400, class 2 is IDR $6,379,600$, class 1 is IDR 7422,900 , and for INA-CBGs of G4-13-III in class 3 is IDR 6,305,300, class 2 is IDR 7,566,400, and class 1 is IDR $8,827,500$.

The admission of hospitalization incurred at Anutapura Hospital varies. It depends on the room class and the stay length of the patient. The total cost of ischemic stroke in class 1 is IDR 71,000,000.00 for 41 inpatients and hemorrhagic stroke patients in class 3 is IDR 24,120,000.00 for 21 inpatients. There is correlation between costs and treatment (Dumpapa, et al., 2010). However, seven hemorrhagic stroke patients received two different treatments at the same time: three patients in class I and ICU, and four patients in class III and ICU. Based on the calculation, the average cost of hospitalization for each treatment class is different, in which the most costly treatment room is the ICU room. The room is used for hemorrhagic stroke patients in critical conditions who require intensive care and continuous monitoring. If the condition has improved, the patient will be transferred based on each treatment class. It is revealed that the actual cost for hemorrhagic stroke was higher than the INA-CBGs rate. On the contrary, ischemic stroke's expense made a huge gap with BPJS insurance. Moreover, its difference could not compensate for the loss generated by hemorrhagic stroke cases.

\section{CONCLUSION}

Ischemic stroke hospitalized patients can not be fully covered by 
BPJS health insurance and are also unbeneficial to cost casualty that has been produced by the actual rate of Hemorrhagic stroke utilization hospital resources. Additionally, there was a significant difference between the total actual cost in the hospital and the INA-CBGs that were proven statistically.

\section{REFERENCES}

Armalina, D., Witjahjo, B., Susilaningsih, N., Purnawati, R. D., Ismail, A., \& Saktini, F. (2020). Screening for Hypertension and Electrocardiography (ECG) for Cardiovascular Diseases Risk. Kemas: Jurnal Kesehatan Masyarakat, 15(3), 303308.

https://doi.org/https://doi.or g/10.15294/kemas.v15i3.17 969.

Baroroh, F., \& Fauzi, L. A. (2017). Analisis Biaya Terapi Stroke pada Pasien Rawat Inap di Rumah Sakit PKU Muhammadiyah Bantul Yogyakarta. Jurnal Ilmiah Ibnu Sina, 2(1), 93-101. https://doi.org/https://doi.or g/10.36387/jiis.v2i1.87.

Budijanto, D., Kurniawan, R., Widiantini, W., Aprianda, R., Mulya, D., Suryani, E., \& Indrawtai, L. (2019). No Title.

Kementerian

Kesehatan RI.

Dourman, K. (2013). Waspadai Stroke Usia Muda. Cerdas Sehat.
Powers, W. J., Derdeyn, C. P., Biller, J., Coffey, C. S., Hoh, B. L., Jauch, E. C., Johnston, K. C., Johnston, S. C., Khalessi, A. A., Kidwell, C. S., Meschia, J. F., Ovbiagele, B., \& Yavagal, D. R. (2015). No Title. Stroke: A Journal of Cerebral Circulation, 46(10), 3020-3035. https://doi.org/https://doi.or g/10.1161/STR.000000000 0000074.

Sofiana, L., \& Rahmawati, D. D. (2019). Hypertension and Diabetes Mellitus Increase the Risk of Stroke. Kemas: Jurnal Kesehatan Masyarakat, 15(2), 147152.

https://doi.org/https://doi.or g/10.15294/kemas.v15i2.14 349.

Specogna, A. V., Turin, T. C., Patten, S. B., \& Hill, M. D. (2017). Hospital treatment costs and length of stay associated with hypertension and multimorbidity after hemorrhagic stroke. $B M C$ Neurology, $\quad$ 17(158). https://doi.org/https://doi.or $\mathrm{g} / 10.1186 / \mathrm{s} 12883-017$ 0930-2.

Suiraoka, I. P. (2012). Penyakit Degeneratif; Mengenal, Mencegah dan Mengurangi Faktor Resiko 9 Penyakit Degeneratif. Nuha Medika.

Yang, F., Zhao, J., \& Xu, H. (2017). Characteristics of Hemorrhagic Stroke 
Muhamad Rinaldhi T, Alwiyah M, Dewi A and Gaby N, Cost Evaluation of ... 296

following Spine and Joint Surgeries. BioMed Research International, 2017(1), 1-6. https://doi.org/10.1155/201

7/5390839 